\title{
INTERNATIONAL TRADE AND CULTURAL Diversity: A MODEL OF PREFERENCE SELECTION
}

\author{
VANKATESH BALA \\ NGO VAN LONG
}

CESIFO WORKING PAPER No. 1242

CATEGORY 7: TRAde Policy

JULY 2004 


\title{
INTERNATIONAL TRADE AND CULTURAL DIVERSITY: A MODEL OF PREFERENCE SELECTION
}

\begin{abstract}
We consider the evolution of preferences when trade occurs between two countries. We show that if one country is much larger than the other, its preferences can eventually take over the preferences of the second country. This result may provide an explanation of why small countries sometimes exclude certain goods (especially those related to culture) from trade agreements. We also show that when the sensitivity of preferences to the relative price is high, the distribution of preferences can fluctuate cyclically over time.
\end{abstract}

JEL Code: D80.

Keywords: preferences, evolution, culture, replicator dynamics, international trade.

Vankatesh Bala

Department of Economics

McGill University

Montreal, H3A $2 T 7$

Canada

vankatesh.bala@mcgill.ca
Ngo Van Long

Economics, AS7-Level 5

5 Arts Link, Shaw Building

National University of Singapore

Singapore 117570

ngo.long@staff.mcgill.ca 


\section{Introduction}

There are many reasons why a country may wish to protect an industry from foreign competition. The arguments that have been put forward in favor of erecting a protectionist barrier (such as tariff or quota) include, among others, the infant-industry argument ${ }^{1}$, the national defense argument, and the cultural identity argument.

Concerns have been expressed in many circles on possible detrimental effects of globalization on cultural diversity. In some countries, policy makers have taken these concerns very seriously. Canada and France are two G7 countries that have in place policies to prevent the possible loss of cultural identity that might result from free trade. France has restrictions on foreign films and television programs from English-speaking countries, while Canada requires minimum level of Canadian content in radio and television broadcast. Canadian magazines are protected by government tax laws that disciminate against Canadian companies that place their advertisements in foreign magazines imported into Canada (in particular, US-based magazines such as Sports Illustrated, Time, etc.). Similarly, South Korea has restrictions on music CD's imported from Japan.

There are, however, very few formal models of effects of trade on culture, or on welfare which includes cultural identity as an argument. Three recent papers stand out. Janeba (2004) formalizes the notion of cultural identity and incorporates it in a Ricardian model of trade. He adopts the "indentity function" formulation of Akerlof and Kranton (2000), whereby (i) a person suffers a utility loss if some individuals in his country deviates from the social norms, and (ii) an individual who deviates from social norms incurs a direct utility loss for the selfinflicted loss of identity (but he may still achieve a net gain in doing so, when the foreign good becomes sufficiently cheap). One of Janeba's results is that trade is not always Pereto superior to autarky. This is because of the public good aspect implied by (i) above. Suranovic

\footnotetext{
${ }^{1}$ See Kemp, 1960, and Clemhout and Wan, 1970, on infant-industry and learning-by-doing.
} 
and Winthorp (2003) present two models of trade when consumers or workers care about culture. In their first model, called the "cultural affinity from work" model, workers in a particular industry receive non-pecuniary cultural benefits (NPCB) from work. If trade liberalization causes this industry to decline, the gains from trade in the case where NPCB exist are smaller than under the standard textbook case. In their second model, called the "cultural externality model," consumption of the home-produced culture good by each person in the home country has a positive external effect on all his compatriots. As a result, the optimal tariff is positive even if the country is a small open economy (even though the tariff is inferior to a consumption subsidy). Francois and Ypersele (2002) consider the protection of a cultural good the production of which involves a fixed cost. A tariff on Hollywood movies can be Pareto superior to free trade if it makes local movies viable.

While arguments for protection must clearly be based on the public goods or externalities associated with the production and/or consumption of cultural goods, in this paper we propose to focus on a different aspect of the problem of trade and culture: the effects of trade on the evolution of preferences. We provide a dynamic model which shows that, in the long run, free trade may result in the demise of cultural diversity: a relatively small country may gradually lose its cultural identity when it engages in free trade with a larger country that has a different preference pattern. Relative world price is endogenous in this model, and changes over time as the distribution of preferences evolves in each economy.

Our approach is essentially based on the biological evolutionary theory, but the model must be interpreted in a broader sense, as it will become clear in what follows. The argument that preferences evolve is basically drawn from the Darwinian theory of evolution ${ }^{2}$, and can readily be seen in the context of animal populations. Suppose that

\footnotetext{
${ }^{2}$ Evolution-based explanation of of the prevalence of certain preference traits in human societies has been provided by Cavalli-Sforza and Feldman (1973), Hirschleifer $(1977,1978)$, Bergstrom (1995), Robson (1996), and others.
} 
there are two species of bears in an island, with one species being essentially fish-eaters, and the other being largely herbivorous. If fish is readily available in the island, then natural selection will favor the former species, while if plant foods are more abundant, the latter species will be selected by evolution. In the long run, the distribution of preferences will reflect relative availability of the different types of food $^{3}$.

While preference selection in the biological sense described in the above paragraph may have been relevant for human populations in the past (and perhaps it may even be applicable to some developing countries today) it is by no means the only way in which natural selection of preferences due to scarcity or abundance arises. Another important cause for preference changes is imitation, which can happen if, for instance, people have preferences for conformity (such as keeping up with the Joneses, etc., see Stephen R. Jones, 1984), or if there are network externalities of the social or informational type (see, e.g., Schelling, 1978, Rogers, 1983, Katz and Shapiro, 1986, Arthur, 1989, Karni and Schmeidler, 1990, Bhikchandani, Hirschleifer, and Welch, 1992). Imitation may be favored by many factors, such as conformity pressure, or relative cheapness. We focus on the latter. If a good is abundant, its price is likely to be low, and the number of users of the good will be high. This in turn increases the possibility of imitation and thereby raises the representation of preferences favoring this good in the population. ${ }^{4}$

Another possibility for natural selection is due to learning-by-doing.

\footnotetext{
${ }^{3}$ The diet of the giant panda is a good example of how selective pressures of this kind operate. See Gould (1987).

${ }^{4}$ Conformity or herd behavior may in some cases be a more important factor. A preference shock in favor of a commodity raises the demand for it, and also raises its price. The former effect may cause a second round of increased demand: more people will consume the good due to conformity pressure. The price rise may be able to provide a powerful countervailing force. We are indebted to a referee for pointing this out. We have decided to focus on the price effect, because it would be unwieldy to develop a model that takes too many factors into account. For a model of trade and culture that emphasizes conformity, see Janeba (2004).
} 
If a good is widely available, it is possible to experiment with it cheaply and thereby find many uses for it. Over time the preferences in the society will move in favor of such a good. A good example is the coconut tree, which is abundant in coastal areas of tropical regions. Nearly every part of the tree has found uses (for lighting, food, drink, clothing and even canoe-making). By contrast, societies which are far away from the seas or located in colder regions of the world will not have well-developed preferences for coconuts or coconut trees.

Finally, habit formation may also induce preference selection. Children growing up in environments where certain habits (such as music appreciation or taste for spicy foods) are prevalent among adults are likely to acquire them as well. Thus these preferences are transmitted across generations (Becker, 1993). The more easily available is the good, the greater the capacity for it to become part of a habit, and the higher is the possibility that such preferences will be selected over time.

Our model is formulated in discrete time. In each period, adults make their consumption decisions, and leave no bequests. This period's chidren are next period's adults. The fitter adults have relatively more "children". "Children" inherit the preference traits of their "parents". Here the words "children" and "parents" must be interpreted in the "cultural sense" rather than the biological sense. Biologically sterile individuals can have "children" in the sense that they can have cultural influence on members of the next generation. Thus, a "gene" may be interpreted in the sense of a cultural gene, that is, a "meme" (a word coined Dawkins, 1986, to mimic the biological concept of gene.) We do not however model the conscious decision of adults to spend resources to spread their "memes". For models along these lines, see Bisin and Verdier $(2000,2001)$ in which "preferences of children are acquired through an adaptation and imitation process which depends on their parents' socialization actions, and on the cultural and social environment in which children live." (Bisin and Verdier, 2001, p.299.)

We begin our analysis by modelling the evolution of preferences 
in an autarkic economy, in which there are two preference types. All individuals have the same endowment bundle consisting of two goods. We show that if the relative supply of the two goods is not too extreme, then there exists a heterogenous distribution ${ }^{5}$ of preferences in the population, which is globally stable. The stability is ensured by the price mechanism interacting with the dynamics of changes in the preference distribution. On the other hand, if the bundle is at one extreme, then one type of preference will be wiped out in the long-run.

After characterizing autarkic equilibrium, we turn to an analysis of trade between two economies with different preference patterns at the time trade opens, and the resulting changes in preferences within each economy. We show that if one economy is much larger than the other, then in the long run the distribution of preferences in the small economy under free trade will be identical to the autarkic long-run pattern of preferences of the large economy, in other words, the small economy will lose its cultural identity. In particular, it is possible that under autarky the small economy has a stable heterogenous distribution of preferences, and under free trade, both countries end up with only one (and the same) preference type.

Before proceeding to the main model, we should pause to comment on related literature on preference changes.

The idea of natural selection of preferences is not new. Becker (1976) discusses the evolution of altruism using the concept of genetic fitness; Hansson and Stewart (1990) mention intergenerational savings in the context of preference selection; Rogers (1994) models the evolution of the rate of time preference by natural selection. Bisin and Verdier $(2000,2001)$ focus on parents' time-allocation decision to socialize their children. In contrast to these papers, our model study the link between relative scarcity of different goods and preference evolution.

\footnotetext{
${ }^{5}$ Bisin and Verdier (2001, p.300) also obtained a stable long-run heterogenous distribution, but they relied on the assumption of substitutability between (a) parents' efforts of socializing their children, and (b) children's cultural adaptation and imitation from society at large.
} 
More generally, our work is related to the literature dealing with the alteration of tastes over time due to social influences or habit formation (see, e.g., Leibenstein, 1950, von Weizsacker, 1971, Pollack, 1976, Becker and Murphy, 1989, Leonard, 1989, Karni and Schmeidler, 1990, and Pesendorfer, 1995). While these papers deal with the evolution of tastes by individuals in partial equilibrium, or in a strategic setting, our paper provides a general equilibrium formulation, with relative price in competitive equilibrium being allowed to influence the future distribution of tastes in the society as a whole. Bell (1994) develops a model of preference evolution in a spatial economy: agents are located on a lattice and modify the parameters of their Cobb-Douglas preferences based upon the consumption pattern in their immediate neighborhood. Bell's paper primarily discusses simulation results ${ }^{6}$, in contrast to our analytical approach.

Finally, we would like to emphasize that the cultural dimension which is investigated in this paper is purely private, in that we have chosen not to incorporate the public good component, as this aspect has been amply dealt with in Janeba (2004) and Suranovic and Winthrop (2003).

\section{Autarky}

\subsection{Basic Assumptions}

Let us begin by considering a closed economy. There are two goods (apples and bananas), two types of individuals (apple lovers and banana lovers). The utility function of the representative apple lover is denoted by $U^{A}(a, b)$ where $a$ and $b$ are the quantities of apples and bananas he consumes. Similarly, the utility function of the representative banana lover is denoted by $U^{B}(a, b)$.

Assumption A1: At any common point $(a, b)$, an apple lover's marginal rate of substitution of bananas for apples is greater than that

\footnotetext{
${ }^{6}$ Our proposition that greater abundance of the endowment of a good leads to its higher representation in the steady state is confirmed by her simulations.
} 
of a banana lover:

$$
M R S^{A}(a, b)=\frac{\partial U^{A}(a, b) / \partial a}{\partial U^{A}(a, b) / \partial b}>\frac{\partial U^{B}(a, b) / \partial a}{\partial U^{B}(a, b) / \partial b}=M R S^{B}(a, b)
$$

For example, starting from a given bundle $(a, b)$, if the left-hand side of inequality (1) is 2 and the right-hand side is $1 / 2$, this signifies that to persuade an apple lover to give up an apple, you must give him two bananas, while to persuade a banana lover to give up an apple, you need to bribe him only half a banana).

Assumption A2: Utility functions are homothetic, strictly quasiconcave, and increasing in each argument. Furthermore, for $i=A, B$,

$$
\begin{aligned}
& \frac{\partial U^{i}(a, b) / \partial a}{\partial U^{i}(a, b) / \partial b} \rightarrow \infty \text { as } \frac{a}{b} \rightarrow 0 \\
& \frac{\partial U^{i}(a, b) / \partial a}{\partial U^{i}(a, b) / \partial b} \rightarrow 0 \text { as } \frac{a}{b} \rightarrow \infty
\end{aligned}
$$

Remark 1: The Cobb-Douglas utility function and the CES utility function satisfies A2.

Assumption A3: Each individual has an endowment vector consisting of 1 apple and $k$ bananas. (Here $k$ is a strictly positive real number.)

Assumption A4: The preferences of the two type of consumers are diametrically opposed, in the sense that, for all pairs of positive real numbers $(x, y)$, we have

$$
U^{A}(x, y)=U^{B}(y, x)
$$

i.e., apple lovers' utility function is a mirror image of banana lovers' utility function.

Example :

$U^{A}(a, b)=\left[\beta a^{\rho}+(1-\beta) b^{\rho}\right]^{1 / \rho}$ and $U^{B}(a, b)=\left[(1-\beta) a^{\rho}+\beta b^{\rho}\right]^{1 / \rho}$ where $\rho<1$.

If we draw indifference curves for the two types, they will cross each other on the 45 degree line, which serves as a "mirror." It follows 
that if the relative price is unity, then both representative individuals will have the same level of utility. (Recall that all individuals have the same endowment vector, and hence the same income.)

Each individual lives for one period. There is a market in each period, where individuals trade, with the objective of maximizing their life-time (i.e. one-period) utility. Individuals take the market relative price as given. After trade, they consume, and they reproduce. Individuals do not bequeath to their offsprings.

The population is denoted by $N_{t}$, which we assume to be constant $N_{t}=N_{t+1}=N$. Let $r_{t}$ denote the proportion of apple lovers in the population at time $t$, and $1-r_{t}$ the proportion of banana lovers in the population at time $t$.

The equilibrium market price of apple (in terms of bananas) in period $t$ is a function of (i) the proportion of apple lovers $r_{t}$ and (ii) the relative supply of bananas, $k$. We write

$$
p_{t}=p\left(r_{t}, k\right)
$$

Now we must make an assumption about the law of motion of $r_{t}$. Here we are assuming replicator dynamics, which has been successfully employed in biology (Hofbauer and Sigmund, 1988) and in evolutionary game theory (see Maitlath, 1992, and references cited therein).

Assumption A5: The law of motion of the proportion of apple lovers in the population is given by

$$
r_{t+1}=f\left(r_{t}\right)=\frac{r_{t}}{r_{t}+\left(1-r_{t}\right) p_{t}}
$$

Remark 2: The replicator dynamics described by (2) has an intuitively plausible interpretation. There will be no change in the proportion of apple lovers (i.e., $\left.r_{t+1}=r_{t}\right)$ if and only if $r_{t}+\left(1-r_{t}\right) p_{t}=1$, i.e., if and only if the relative price of apple is unity. If for some reason the relative price of apple is greater than unity, apple lovers will be at a disadvantage relative to banana lovers. This will reduce their fitness, and consequently, their reproduction rate will be lower relative to that 
of banana lovers. The rule (2) means that the future share of apple lovers in the population depends positively on the current share (for given $p_{t}$ ) and negatively on the current price of apple, $p_{t}$. However, we should note that the current $p$ depends on the current $r$, through demand and supply interaction.

As we have discussed in the introduction, the word "offsprings" should not be interpreted as biological children. Here we are talking about cultural influences. People who are "less fit" will have less influence on the younger people they come into contact with. Take the example of Quebec, where both French and English newspapers, magazines, and books are read. If French-language books become relatively more expensive than English-language books, the proportion of people whose preferences are biased toward French-language books will tend to fall, even though the biological reproduction rates are roughly the same for all groups. Of course our model is very simple and cannot capture all the real world features. In particular, we do not model parents' resource allocation decisions ${ }^{7}$ such as the time spent with the child, the school to which the child is sent, etc.

Remark 3: If we write $s_{t}=1-r_{t}$, and $q_{t}=1 / p_{t}$, then it follows from (2) that

$$
s_{t+1}=\frac{s_{t}}{s_{t}+\left(1-s_{t}\right) q_{t}}
$$

It follows that Assumption 5 is not biased in favor of any good, or any preference type, and that the choice of the numeraire has no bearing on the results.

\subsection{Market clearing price in a closed economy}

In any period $t$, given $r_{t}$ and $k$, we can define a relative price $p^{A}(k)$ (of apple in terms of bananas) at which apple lovers' net demand for

\footnotetext{
${ }^{7}$ These factors are discussed in Bisin and Verdier (2001, pp 306-307), but only a reduced form model is used.
} 
apples is zero. This price is given by

$$
p^{A}(k)=\frac{\partial U^{A}(1, k) / \partial a}{\partial U^{A}(1, k) / \partial b}
$$

At any relative price $p>p^{A}(k)$, apple lovers will be net sellers of apples, and at any price $p<p^{A}(k)$, they will be net buyers of apples. We call $p^{A}(k)$ the self-sufficiency price of apple lovers.

Similarly, we define a relative price $p^{B}(k)$ (of apple in terms of bananas) at which banana lovers' net demand for apples is zero:

$$
p^{B}(k)=\frac{\partial U^{B}(1, k) / \partial a}{\partial U^{B}(1, k) / \partial b}
$$

At any relative price $p>p^{B}(k)$, banana lovers will be net sellers of apples, and at any price $p<p^{B}(k)$, they will be net buyers of apples. We call $p^{B}(k)$ the self-sufficiency price of banana lovers.

Clearly, from Assumption A1, we have

$$
p^{A}(k)>p^{B}(k)>0 .
$$

The following result can be proved:

Lemma 1: Under Assumptions A1 to A3, for each $r_{t} \in[0,1]$, and each $k>0$, there exists a unique market clearing price $p_{t}=p\left(r_{t}, k\right)$. This price has the following properties. First, it lies between the two self-sufficiency prices:

$$
p^{A}(k) \geq p\left(r_{t}, k\right) \geq p^{B}(k)>0
$$

Second, the greater is the proportion of apple lovers, the higher is the market clearing price of apple (in terms of bananas):

$$
\frac{\partial p\left(r_{t}, k\right)}{\partial r_{t}}>0
$$

Third, the greater the endowment of bananas per person, the higher is the market clearing price of apple (in terms of bananas):

$$
\frac{\partial p\left(r_{t}, k\right)}{\partial k}>0
$$


Proof: see the Appendix.

Remark 4: The intuition behind Lemma 1 is straightforward. An increase in $r_{t}$ will increase the aggregate relative demand for apples, and thus the relative price of apple will rise. An increase in $k$ will reduce the aggregate relative supply for apples, and thus the relative price of apple will rise.

Next, we note that the self-sufficient prices $p^{A}(k)$ and $p^{B}(k)$ are increasing functions of the relative abundance of bananas, as measured by $k$. It follows from Assumptions A1 to A3 that there exist two positive numbers $k^{B}$ and $k^{A}$ such that

$$
p^{A}\left(k^{A}\right)=1 \text { and } p^{B}\left(k^{B}\right)=1
$$

where $k^{B}>1>k^{A}$.

The following lemma can be proved:

Lemma 2: (i) if the endowment of bananas per person is smaller than $k^{A}$, then the market clearing price of apple (in terms of bananas) is less than unity, regardless of the actual value $r_{t} \in[0,1]$ :

$$
p(r, k)<1 \text { for all } k<k^{A}
$$

(ii) if the endowment of bananas per person exceeds $k^{B}$, then the market clearing price of apple (in terms of bananas) is greater than unity, regardless of the actual value $r_{t} \in[0,1]$ :

$$
p(r, k)>1 \text { for all } k>k^{B}
$$

(iii) if the endowment of bananas per person is in the open interval $\left(k^{A}, k^{B}\right)$, then there exists a unique value $r^{*}(k) \in(0,1)$ such that

$$
p\left(r^{*}(k), k\right)=1
$$

and $p(r, k)>1$ for $r>r^{*}(k)$ while $p(r, k)<1$ for $r<r^{*}(k)$.

Proof: One can construct a simple diagram where relative consumption is measured along the horizontal axis and relative price, $p$, is 
measured along the vertical axis. The relative demand curve $R^{A}(p)$ (of apples to bananas) of the representative apple lover is downward sloping, and lies everywhere above the relative demand curve $R^{B}(p)$ of the representative banana lover. The intersection between the horizontal line $p=1$ and the curve $R^{A}(p)$ (respectively, $R^{B}(p)$ ) yields the value $1 / k_{A}$ (respectively $1 / k_{B}$ ) on the horizontal axis. Thus $1 / k_{A}>1 / k_{B}$. The market clearing price is where the relative supply curve intersects the aggregate relative demand curve (which lies between the two curves $R^{A}(p)$ and $\left.R^{B}(p)\right)$. Thus if $k>k_{A}$, the relative supply curve (of apples to bananas) must intersect the aggregate relative demand curve at some $p<1$. Similarly, if $k<k_{B}$, the relative supply curve (of apples to bananas) must intersect the aggregate relative demand curve at some $p>1$. This proves (i) and (ii). Part (iii) follows.

Remark 5: It can be shown that $r^{*}(k)$ is decreasing in $k$.

\subsection{Evolution of preference distribution in a closed economy}

We want to determine the evolution of the proportion of apple lovers over time. From the postulated replicator law (2), if $r_{t}=0$, then $r_{t+\tau}=0$ for all positive integer $\tau$. Similarly, if $r_{t}=1$ then $r_{t+\tau}=1$ for all positive integer $\tau$. Thus $r=0$ and $r=1$ are two fixed points of the mapping $f($.$) . Are there any other fixed points? The$ answer is given in Proposition 1:

Proposition 1:(multiplicity of fixed points)

(i) if $k \leq k^{A}$ then there are only two fixed points, $r=0$ and $r=1$

(ii) if $k \geq k^{B}$, then there are only two fixed points, $r=0$ and $r=1$

(iii) if $k \in\left(k^{A}, k^{B}\right)$ then there are only three fixed points: $r=0$, $r=1$ and $r=r^{*}(k)$ where $r^{*}(k)$ satisfies $p\left(r^{*}(k), k\right)=1$.

Proof: A fixed point is a value $\widehat{r}$ such that

$$
\widehat{r}=\frac{\widehat{r}}{\widehat{r}+(1-\widehat{r}) p(\widehat{r}, k)}
$$

Clearly, $\widehat{r}=1$ and $\widehat{r}=0$ both satisfy equation (3). Any other fixed point $\widehat{r}$ in $(0,1)$ must satisfy

$$
\widehat{r}+(1-\widehat{r}) p(\widehat{r}, k)=1
$$


The left-hand side of (4) is a weighted average of 1 and $p(\widehat{r}, k)$. Thus for the left-hand side to equal the right-hand side, it must be the case that $p(\widehat{r}, k)=1$. If $k<k^{A}$, then $p(r, k)>1$, thus violating (4). If $k>k^{B}$, then $p(r, k)<1$ thus violating (4). If $k=k^{A}$, then $p\left(\widehat{r}, k^{A}\right)=1$ only if $\widehat{r}=1 . k=k^{B}$, then $p\left(\widehat{r}, k^{B}\right)=1$ only if $\widehat{r}=0$. Finally, if $k \in\left(k^{A}, k^{B}\right), p(\widehat{r}, k)=1$ at a unique $\widehat{r}(k)$ by virtue of Lemma 2.

Remark 6: Proposition 1 is about the existence of fixed points. To study the stability of fixed points, we must make an additional assumption.

From (2) we calculate

$$
f^{\prime}(r)=\frac{p(r, k)-r(1-r) p_{r}(r, k)}{[r-p(r, k)(1-r)]^{2}}
$$

Assumption A6: if the proportion of apple lovers rises by $x$ per cent, then the market clearing price of apple will rise by less than $x /(1-r)$ per cent:

$$
\left[\frac{r}{p(r, k)}\right] \frac{\partial p(r, k)}{\partial r}<\frac{1}{1-r}
$$

Remark 7: The Cobb-Douglas utility functions satisfy Assumption A6. This assumption ensures that $f^{\prime}(r)>0$.

Proposition 2:(possible heterogeneity of steady state preferences)

Suppose $r_{0} \in(0,1)$. Under Assumptions A1 to A6,

(i) if the banana endowment is small, such that $k \leq k^{A}$, then $r_{t}$ will converge to unity, i.e., banana lovers will become extinct in the long run.

(ii) if the banana endowment is large, such that $k \geq k^{B}$, then $r_{t}$ will converge to zero, i.e., apple lovers will become extinct in the long run.

(iii) if $k \in\left(k^{A}, k^{B}\right)$, then the proportion of apple lovers will converge to a finite number $r^{*}(k) \in(0,1)$. 
Proof: See the Appendix.

Remark 8: Part (iii) of Proposition 2 implies that there exists a stable steady state that exhibits heterogeneity of preferences if the initial endowments of the two goods are relatively close to each other (i.e., the ratio of bananas to apples in the endowment bundle is neither very great, nor very small). The intuition underlying this result is as follows: as the evolutionarily favored preference type increases its representation in the population, this increase raises the demand for the good which this preference type prefers, thereby raising its price and causing the other preference type to gain an evolutionary advantage. Provided the relative endowment of one good to the other is neither too great, nor too small, this negative feedback effect is sufficiently strong to ensure that neither type becomes extinct in the long run, i.e., heterogeneity prevails ${ }^{8}$.

There is a direct relationship between the relative abundance of bananas and the proportion of apple lovers in the steady state. When bananas are very scarce (i.e., $k \leq k^{A}$ ) the relative price of apples is low, so that apple lovers are evolutionary selected to the extent that banana lovers become extinct. Thus, with $k \leq k^{A}$, the unique stable restpoint is $r=1$. When the endowment of bananas is in the intermediate range $\left(k^{A}<k<k^{B}\right)$, the price of apples rises sufficiently when there are a large number of apple lovers to ensure that neither preference type can become extinct in the long run. Furthermore, the larger the availability of bananas in the economy, the greater the representation of banana lovers in the steady state. Finally, if the endowment of bananas is very large $\left(k \geq k^{B}\right)$, the relative price of apples is so high that natural selection drives apple lovers to extinction.

Discussion: We have made use of the negative feedback that results from the price mechanism to establish a stable equilibrium with heterogenous preferences. A similar negative feedback operates in the model of Bisin and Verdier (2001, p. 303), but their negative feed-

\footnotetext{
${ }^{8}$ Preference cycles may exist if we modify Assumption A5 so that the denominator of the dynamic rule (2) becomes non-linear in price. See Appendix II for this generalization.
} 
back relies instead on the assumption that vertical cultural transmission and oblique cultural transmission are cultural substitutes. There is no endogenous relative price of goods in their model. When vertical cultural transmission and oblique cultural transmission are cultural complements, their interior equilibrium is completely unstable (their Figure 2). We could generate a completely unstable interior equilibrium in a modified version of our model by allowing for phenomena such as conformism and herd behavior. However, this would detract from our focus on standard relative supply and relative demand interactions.

\section{Trade between two economies}

Consider two countries, say home $(H)$ and foreign $(F)$. In each country, there are apple lovers and banana lovers. The utility function of each type of individual is the same regardless of the country they live in. The home country is as described in the preceding section. In $H$, each individual is born with an endowment vector $(1, k)$ (one apple, and $k$ bananas). In the foreign country $F$, each individual is born with an endowment vector $(\delta, 1)$ (one banana and $\delta$ apples) where $\delta>0$. A high value of $\delta$ indicates the relative abundance of apples in this country. The population in $H$ is $N_{t}=N$ and the population in $F$ is $M_{t}=M$. The parameter $m=M / N$ reflects the relative size of country $F$.

Let $r_{t}^{i}$ denote the proportion of apple lovers in the population of country $i$. $(i=H, F)$. The dynamic evolution for the home country under autarky is given by

$$
r_{t+1}^{H}=\frac{r_{t}^{H}}{r_{t}^{H}+\left(1-r_{t}^{H}\right) p\left(r_{t}^{H}, k\right)}
$$

where $p\left(r_{t}^{H}, k\right)$ is the home country market clearing price under autarky. From Proposition 2, we know that if $k \geq k^{B}$, then in the long run, under autarky, banana lovers will dominate (there will be no apple lovers left.) On the other hand, if $k \in\left(k^{A}, k^{B}\right)$ then the home 
country will exhibit heterogeneous preferences in the long run. We admit both cases.

We now turn to the foreign country. First, consider the foreign country under isolation. The evolution in this country is given by

$$
r_{t+1}^{F}=\frac{r_{t}^{F}}{r_{t}^{F}+\left(1-r_{t}^{F}\right) p\left(r_{t}^{F}, 1 / \delta\right)}
$$

where $p\left(r_{t}^{F}, 1 / \delta\right)$ is the foreign country market clearing price under autarky. By a familiar argument, there exists two positive numbers $\delta^{A}$ and $\delta^{B}$ such that the self-sufficiency price ratios for the two types of consumers satisfy

$$
p^{A}\left(1 / \delta^{A}\right)=1 \text { and } p^{B}\left(1 / \delta^{B}\right)=1 .
$$

where $\delta^{A}>1>\delta^{B}$. (In fact, $\delta^{A}=1 / k^{A}$ and $\delta^{B}=1 / k^{B}$ ). Clearly, if $\delta \geq \delta^{A}$ then under autarky, in the long run the preferences of apple lovers will dominate in country $F$.

We can now consider the effect of trade on these two economies. Suppose that $k \geq k^{B}$ and $\delta \geq \delta^{A}$ and that the economies have been autarkic until some large time $T$, after which they start to trade. Under these circumstances, the proportion of banana lovers in the home country will be close to unity, while the proportion of apple lovers in the foreign country will be close to unity.

We can then show that if the foreign economy is sufficiently large relative to the home economy (a large $m$ ), then free trade between the two countries will lead to the eventual extinction of banana lovers in the home country.

Let $p^{w}\left(r^{H}, r^{F}, k, \delta, m\right)$ denote the market clearing world price. To ensure that this equilibrium is unique, we need the following assumption:

Assumption A7: In each country $i$, the excess demand function for apples is downward sloping at every $p>0$, at all $r^{i} \in[0,1]$.

Remark 9: Assumption A7 is satisfied if the utility functions are Cobb-Douglas, or $C E S$ with elasticity of substitution greater than unity. 
In this world economy, the dynamics are given by a system of two difference equations:

$$
\begin{aligned}
& r_{t+1}^{H}=\frac{r_{t}^{H}}{r_{t}^{H}+\left(1-r_{t}^{H}\right) p^{w}\left(r_{t}^{H}, r_{t}^{F}, k, \delta, m\right)}, \text { for } t \geq T \\
& r_{t+1}^{F}=\frac{r_{t}^{F}}{r_{t}^{F}+\left(1-r_{t}^{F}\right) p^{w}\left(r_{t}^{H}, r_{t}^{F}, k, \delta, m\right)}, \text { for } t \geq T .
\end{aligned}
$$

We can then prove the following proposition:

Proposition 3:(The demise of cultural diversity) Assume $\delta \geq \delta^{A}$. For any given initial vector $\left(r_{T}^{H}, r_{T}^{F}\right)$ that is strictly positive, there exists an $m^{*}>0$ such that if $m>m^{*}$, then in the long run there will only be apple lovers in each country (i.e., the banana lovers will vanish in the long run.)

Remark 10: An implication of Proposition 3 is that if the home country starts at an autarkic long-run steady state with heterogenous preferences and decides to open trade with the foreign country, then eventually whole world will end up with only one preference type left: that of the large country. ${ }^{9}$

The intuition behind Proposition 3 is as follows.It is assumed that the foreign country has a large endowment of apples. Thus, if the foreign country is much larger than the home country, the equilibrium price of apple under free trade will be very low (i.e., bananas will be very expensive) and consequently the banana lovers in both economies will become extinct.

\section{Conclusions}

We have considered a simple model of preference evolution in a society with two goods and two preference types. The distribution of preferences changes in response to changes in the relative price. We

\footnotetext{
${ }^{9}$ As pointed out by a referee, an alternative reading of Proposition 3 is that when two social classes are integrated, the rich class, if it is rich enough, will end up by culturally dominating the poor class.
} 
show that when the endowment of one of the goods in the society is small, the unique stable steady state involves the extinction of of the preference type which exhibits a relative liking for the good in limited supply. When the endowments of the two goods are closed to each other, both preference types are represented in the long-run equilibrium.

Within this framework, we consider the impact of trade upon two societies which have previously evolved in isolation and consequently have very different preferences. We show that if one of the country is large, its preferences will eventually drive the other's preferences to extinction.

Acknowledgements: We wish to thank Alan Deardorff, Prajit Dutta, Ronald Findlay, Sanjeev Goyal, Joseph Greenberg, Franque Grimard, Leonid Hurwicz, Ronald W. Jones, Kim Long, Debraj Ray, Henry Wan Jr., Ping Wang, and two referees for helpful comments and suggestions. Financial supports from SSHRC and FQRSC are gratefully acknowledged. 


\section{APPENDIX I}

\section{A.PROOF OF LEMMA 1}

We show the existence and uniqueness of the market clearing price $p(r, k)$, and then obtain its comparative static properties. Fix $k>0$. Recall that the self-sufficiency price ratios satisfy $p^{A}(k)>p^{B}(k)$. For any price $p>p^{A}(k)$, the apple lovers will be net sellers of apples, and so will be banana lovers. So the equilibrium price cannot be above $p^{A}(k)$. A similar argument show that the equilibrium price cannot be below $p^{B}(k)$. Clearly, if $r=1$ or $r=0$, then the unique competitive price is $p^{A}(k)$ or $p^{B}(k)$ respectively. In what follows, we consider $r \in(0,1)$.

It will be convenient to use a slightly more general notation, where each individual in this economy has an endowment bundle $(g, k)$ which consists of $g$ apples and $k$ bananas. (Later, we set $g=1$ ).

Each agent's income in terms of bananas is $I(p, g, k)=p g+k$. (Here, $g$ means $g$ apples, and $k$ means $k$ bananas). Let $x^{A}(p, I(p, g, k))$ denote the Marshallian demand function for apples by a representative apple lover, and $x^{B}(p, I(p, g, k))$ the Marshallian demand function for apples by a representative banana lover. The economy-wide per capita excess demand for apples is

$$
z(p ; r, g, k)=r\left[x^{A}(p, I(p, g, k))-g\right]+(1-r)\left[x^{B}(p, I(p, g, k))-g\right]
$$

This function is continuous. Now set $g=1$. Recall $z(p ; r, 1, k)$ is negative at $p^{A}(k)$ and positive at $p^{B}(k)$. Thus, by the mean value theorem, there exists a value $p^{*} \in\left(p^{B}(k), p^{A}(k)\right)$ at which $z=0$. To show uniqueness, we must establish that the slope of $z\left(p^{*}\right)$ is negative when $z\left(p^{*}\right)=0$. Using the Slutsky equations (see, for example, Varian, Chapter 9) we can write

$$
\begin{gathered}
z_{p}(p ; r, 1, k)=r h_{p}^{A}+(1-r) h_{p}^{B}+ \\
r\left(1-x^{A}\right) \frac{\partial x^{A}(p, I(p, 1, k))}{\partial I}+(1-r)\left(1-x^{B}\right) \frac{\partial x^{B}(p, I(p, 1, k))}{\partial I}
\end{gathered}
$$


where $h^{i}($.$) are Hicksian demand functions, and h_{p}^{i}<0$. We now show that, evaluated at $p^{*}$, the sum of the last two terms on the right-hand side of the above expression is negative. Note that at $p^{*}$, type A's excess demand for apples is posittive, thus $1-x^{A}<0$. Now, since utility functions are assumed to be homothetic, the Marshallian deman functions must be of the form

$$
x^{A}(p, I)=\alpha^{A}(p) I \text { and } x^{B}(p, I)=\alpha^{B}(p) I
$$

where $\alpha^{A}(p)>\alpha^{B}(p)$. Thus, at $p^{*}$

$r\left(1-x^{A}\right) \frac{\partial x^{A}(p, I(p, 1, k))}{\partial I}=r\left(1-x^{A}\right) \alpha^{A}(p)<r\left(1-x^{A}\right) \alpha^{B}(p)=(1-r)\left(1-x^{B}\right) \alpha^{B}(p)$

This shows that the sum of the last two terms on the right-hand side of (6) is negative. It follows that $z^{\prime}(p)<0$ at $p^{*}$.

The comparative static results follow easily. Thus

$$
\frac{\partial p^{*}}{\partial r}=-\frac{z_{r}}{z_{p}}>0
$$

where $z_{r}=x^{A}(p, I(p, 1, k))-x^{B}(p, I(p, 1, k))>0$. And

$$
\frac{\partial p^{*}}{\partial k}=-\frac{z_{k}}{z_{p}}>0
$$

where $z_{k}=r \alpha^{A}(p)+(1-r) \alpha^{B}(p)>0$.

\section{B. PROOF OF PROPOSITION 2}

From Lemma 2, if banana endowment is small such that $k<k^{A}$ then $p(r ; k)<1$, which implies $f(r) \in(r, 1)$ whenever $r \in(0,1)$, Thus $r_{t}$ increases to a limit point $\widehat{r}$ which must be equal to 1 . Part (ii) is proved by a similar argument. To show part (iii), we note that there are now three fixed points, at $r=0, r=1$ and $r=r^{*}(k)$. It is clear that for $r \in\left(0, r^{*}(k)\right)$ we have $f(r)>r$ because $p(r ; k)<1$ in this range. Likewise, for $r \in\left(r^{*}(k), 1\right)$ we have $f(r)<r$ because $p(r ; k)>1$ in this range. For any $r_{0} \in\left(0, r^{*}(k)\right)$, we have $r_{1}=$ 
$f\left(r_{0}\right)>r_{0}$ and since $f^{\prime}(r)>0$ (by Assumption A6) the sequence $r_{t}$ increases monotonically to a fixed point in $\left[0, r^{*}(k)\right]$ which must be $r^{*}(k)$. A similar argument shows that if $r_{0} \in\left(r^{*}(k), 1\right)$, the sequence $r_{t}$ decreases monotonically to $r^{*}(k)$.

\section{PROOF OF PROPOSITION 3}

Using the notation in (5), Country $H$ 's per capita excess demand function for apples is now denoted as

$$
z^{H}\left(p ; r^{H}, 1, k\right)
$$

and country $F$ 's per capita excess demand function for apples is

$$
z^{F}\left(p ; r^{F}, \delta, 1\right)
$$

Let $m=M / N$. Denote the world excess demand function for apples under trade as

$$
\begin{gathered}
Z\left(p, r^{H}, r^{F}, m, N, \delta, k\right)=N z^{H}\left(p ; r^{H}, 1, k\right)+M z^{F}\left(p ; r^{F}, \delta, 1\right) \\
=m N\left\{\frac{z^{H}\left(p ; r^{H}, 1, k\right)}{m}+z^{F}\left(p ; r^{F}, \delta, 1\right)\right\}
\end{gathered}
$$

Consider the following Lemma:

Lemma A3: Consider the country $F$ in isolation. If $\delta>\delta^{A}$, there exists $\pi \in(0,1)$ and $\tau<0$ such that for all $p \geq \pi$ and all $r^{F} \in[0,1]$ we have $z^{F}\left(p, r^{F}, \delta, 1\right) \leq \tau<0$.

Proof of the lemma: Since $\delta>\delta^{A}, p^{A}(1 / \delta)<1$. Choose $\pi \in$ $\left(p^{A}(1 / \delta), 1\right)$. Given any $p>\pi$, and $r^{F} \in[0,1]$, apple lovers will be net suppliers of apples. The same is true for banana lovers. Hence for any $p>\pi$ and any $r^{F} \in[0,1]$,

$0=z^{F}\left(p^{A}(1 / \delta), 1, \delta, 1\right)>z^{F}(\pi, 1, \delta, 1) \geq z^{F}\left(\pi, r^{F}, \delta, 1\right) \geq z^{F}\left(p, r^{F}, \delta, 1\right)$

Choose $\tau$ to be $z^{F}\left(\pi, r^{F}, \delta, 1\right)$. The result follows.

Proof of the proposition: From assumption A7, $Z\left(p, r^{H}, r^{F}, m, N\right)$ is downward sloping. Thus there exists a unique equilibrium world 
price $p^{w}\left(r^{H}, r^{F}, k, \delta, m\right)$. Since $z^{H}$ is increasing in $r^{H}$ and decreasing in $p$, we have for all $r^{H} \in[0,1]$ and all $p \geq p^{A}(1 / \delta)$ that

$$
z^{H}\left(p^{A}(1 / \delta), 1,1, k\right) \geq z^{H}\left(p^{A}(1 / \delta), r^{H}, 1, k\right) \geq z^{H}\left(p, r^{H}, \delta, 1, k\right)
$$

Choose $m^{*}$ such that $z^{H}\left(p^{A}(1 / \delta), 1,1, k\right) / m^{*} \leq-\tau / 2$. This ensures by (7) that for all $r^{H} \in[0,1]$, and all $p>p^{A}(1 / \delta)$ we have $z^{H}(p, 1,1, k) / m^{*}<-\tau / 2$ as well. Recall from Lemma A3 that (i) $p^{A}(1 / \delta)<1$ and (ii) there is $\pi \in\left(p^{A}(1 / \delta), 1\right)$ such that for all $p \geq \pi$ we have $Z^{F}\left(p, r^{F}, 1\right) \leq \tau$. It follows that when $m \geq m^{*}$ then

$$
z^{F}\left(p, r^{F}, \delta, 1\right)+\frac{z^{H}\left(p, r^{H}, 1, k\right)}{m} \leq \tau-\frac{\tau}{2} \leq \frac{\tau}{2}<0
$$

given $r^{H}$ and $r^{F} \in[0,1]$ and $p \geq \pi$. Hence the unique equilibrium $p^{w}\left(r^{H}, r^{F}, k, \delta, m\right) \leq \pi<1$. The result now follows from the fact that as the equilibrium price is strictly less than 1 , both $r_{t}^{H}$ and $r_{t}^{F}$ must monotonically increase to 1 .

\section{APPENDIX II: PREFERENCE CYCLES}

In assumption A5, we specified a replicator dynamic where the relative price appears linearly in the denominator. It is worthwhile to generalize this specification, by allowing the possibility that the relative price appears in the denominator in a non-linear fashion.

It turns out that such generalization can generate preference cycles. To show this, let $\phi(p)$ be a sign-preserving monotone increasing function of $p$, with $\phi(1)=1$. We specify the following replicator dynamics law:

$$
r_{t+1}=\frac{r_{t}}{r_{t}+\left(1-r_{t}\right) \phi\left(p_{t}\right)}
$$

Thus, as in the special law (2), we get $r_{t+1}=r_{t}$ if and only if $p_{t}=1$. Recall that $s_{t}=1-r_{t}$. The law (8) implies

$$
s_{t+1}=\frac{s_{t}}{s_{t}+\frac{\left(1-s_{t}\right)}{\phi\left(p_{t}\right)}}
$$


For symmetry, it makes sense to suppose

$$
s_{t+1}=\frac{s_{t}}{s_{t}+\left(1-s_{t}\right) \phi\left(q_{t}\right)}
$$

For this to hold, it is necessary and sufficient that

$$
\frac{1}{\phi(p)}=\phi(1 / p)
$$

This property is satisfied if

$$
\phi(p)=p^{\lambda}
$$

where $\lambda>0$. The special case $\lambda=1$ would yield the rule (2). In general, the greater is the value of $\lambda$, the higher is the relative fertility response of apple lovers to the price of apples.

In what follows, we will assume

$$
r_{t+1}=\frac{r_{t}}{r_{t}+\left(1-r_{t}\right)\left(p_{t}\right)^{\lambda}}=f_{\lambda}\left(r_{t}\right)
$$

To show the possibility of preference cycles in a closed economy, we provide an example with the Cobb-Douglas specification

$$
U^{A}(a, b)=a^{\theta} b^{1-\theta} \text { while } U^{B}(a, b)=a^{1-\theta} b^{\theta} \text { where } \theta \in(1 / 2,1)
$$

In this case, the market clearing price can be computed:

$$
p(r, k)=\frac{[1-\sigma(r)] k}{\sigma(r)}
$$

where $\sigma(r)=\theta+r-2 \theta r$. Note that $\sigma(r)$ is decreasing in $r$ because $\theta \in(1 / 2,1)$. In particular, $\sigma(0)=\theta$ and $\sigma(1)=1-\theta$. We can also explicitly calculate

$$
k^{A}=\frac{1-\theta}{\theta}<1
$$

and

$$
k^{B}=\frac{\theta}{1-\theta}>1
$$


Moreover, for $k \in\left(k^{A}, k^{B}\right)$, we can explicitly calculate the fixed point $r^{*}(k)$ :

$$
r^{*}(k)=\frac{\theta-k(1-\theta)}{(2 \theta-1)(1+k)}
$$

This is a decreasing function of $k$ in that interval. (Note that $r^{*}(k)$ is independent of $\lambda>0$, because $p(r, k)^{\lambda}=1$ if and only if $p(r, k)=1$.)

Clearly the dynamic behavior of $f_{\lambda}($.$) is the same as in Proposition$ 2 if $k \leq k^{A}$ or if $k \geq k^{B}$. We now consider the case where $k \in\left(k^{A}, k^{B}\right)$. In this case, the dynamics depends on the parameter $\lambda$. We note that

$$
f_{\lambda}^{\prime}(r)=\frac{k p(r, k)^{\lambda}[\sigma(r)(1-\sigma(r))-\lambda r(1-r)(2 \theta-1)]}{\left(r+(1-r) p(r, k)^{\lambda}\right)^{2} \sigma(r)^{2}}
$$

and

$$
f_{\lambda}^{\prime}(0)=\left[\frac{k^{B}}{k}\right]^{\lambda}>1 \text { and } f_{\lambda}^{\prime}(1)=\left[\frac{k}{k^{A}}\right]^{\lambda}>0 \text { for } k \in\left(k^{A}, k^{B}\right)
$$

Note that every term on the right-hand side of equation (11) is positive, with the possible exception of the term inside the square brackets. The sign and magnitude of this term is important in determining the dynamics. Let us call this term $g(r)$ :

$$
g(r)=\sigma(r)(1-\sigma(r))-\lambda r(1-r)(2 \theta-1)
$$

We note that $g(0)=g(1)=\theta(1-\theta)>0$, and

$$
\begin{gathered}
g^{\prime}(r)=(2 r-1)(\lambda-(2 \theta-1))(2 \theta-1) \\
g^{\prime \prime}(r)=2(\lambda-(2 \theta-1))(2 \theta-1)
\end{gathered}
$$

There are two cases:

Case 1: $\lambda<2 \theta-1$

In this case, the function $g(r)$ is strictly concave and reaches its maximum at $r=1 / 2$. Thus, for all $r \in[0,1], g(r) \geq g(0)>0$. It 
follows that $f_{\lambda}^{\prime}(r)>0$ for all $r \in[0,1]$. Since $r^{*}(k)$ is the only fixed point of $f_{\lambda}$ in the open interval $(0,1)$, we deduce from (12) that

$$
0<f_{\lambda}^{\prime}\left(r^{*}\right)<1
$$

Thus $f_{\lambda}$ is strictly monotone increasing and satisfies $f_{\lambda}(r)>r$ for $r \in\left(0, r^{*}\right)$ and $f_{\lambda}(r)<r$ for $r \in\left(r^{*}, 1\right)$. It follows that the dynamics are very similar to Proposition 2. (The same conclusion applies if $\lambda=2 \theta-1$.)

Case $2: \lambda>2 \theta-1$. In this case, the function $g(r)$ is strictly convex and reaches its minimum at $r=1 / 2$. Thus, for all $r \in[0,1]$,

$$
g(r) \geq g(1 / 2)=\frac{1-\lambda(2 \theta-1)}{4}
$$

Define

$$
\lambda^{*}=\frac{1}{2 \theta-1}>0
$$

Sub-case 2a: $\lambda<\lambda^{*}$. Then for all $r \in[0,1], g(r)>0$, and hence $f_{\lambda}^{\prime}(r)>0$. It follows that $0<f_{\lambda}^{\prime}\left(r^{*}\right)<1$ and the dynamics are very similar to Proposition 2.

Sub-case 2b: $\lambda>\lambda^{*}$. In this case $g(1 / 2)<0$ so $f_{\lambda}$ is no longer strictly increasing. We shall study this case by considering the local stability of the fixed points.

The following Proposition follows from our analysis of Case 1 and Sub-case 2a:

Proposition 4: (Case $\lambda<\lambda^{*}$ )

Suppose $k \in\left(k^{A}, k^{B}\right)$ and $r_{0} \in(0,1)$, and the law of motion is $r_{t+1}=f_{\lambda}\left(r_{t}\right)$. If $\lambda<\lambda^{*}$ then

(i) $r_{t}$ converges to $r^{*}$ from below, for $r_{0} \in\left(0, r^{*}\right)$

(ii) $r_{t}$ converges to $r^{*}$ from above, for $r_{0} \in\left(r^{*}, 1\right)$.

We now turn to subcase $2 \mathrm{~b}$. We define

$$
\lambda^{* *}(k)=\frac{2 k(2 \theta-1)}{\theta(1-\theta)\left[k^{B}(\theta) k-1\right]\left[1-k^{A}(\theta) k\right]}>0
$$

Proposition 5: (Case $\lambda>\lambda^{*}$ ) 
Suppose $k \in\left(k^{A}, k^{B}\right)$ and $r_{0} \in(0,1)$, and the law of motion is $r_{t+1}=f_{\lambda}\left(r_{t}\right)$. If $\lambda>\lambda^{*}$ then

(i) for $\lambda<\lambda^{* *}(k), r^{*}$ is locally asymptotically stable.

(ii) for $\lambda>\lambda^{* *}(k)$, the fixed point $r^{*}$ is not locally asymptotically stable; there is no locally asymptotically stable equilibrium.

Remark 10: It can be shown that $\lambda^{* *}$ is strictly decreasing in $\theta$ for $\theta \in(1 / 2,1)$. As $\theta \rightarrow 1, \lambda^{* *} \rightarrow 2$.Thus, the more extreme the preferences (values of $\theta$ close to 1 ), the more easy it is for instability to arise.

We now show the possibility of cycles.i.e., that the proportions of the two preference types can fluctuate over time. To demonstrate this in a simple manner, we fix the value of $\theta$.Let $\theta=9 / 10$. (Thus $k^{A}=1 / 9$ and $\left.k^{B}=9\right)$. In what follows, $f_{\lambda}\left(f_{\lambda}(r)\right)$ is denoted as $f_{\lambda}^{2}(r)$. We have

Proposition 6: (two-period cycles).

Suppose $\theta=9 / 10$ and $k \in(1 / 9,9)$. For almost all value of $k$ in $(1 / 9,9)$, there exists a neighborhood $N$ around $r^{*}$ such that for all $r \in N-\left\{r^{*}\right\}$, there exists $\lambda(r)$ such that two-period cycles obtain, i.e. $f_{\lambda(r)}^{2}(r)=r$ and $r$ is not a fixed point.

Proof: Following Devaney (1989, Theorem 12.7. page 90), we wish to show that

$$
\frac{\partial\left(f_{\lambda}^{2}\right)^{\prime}\left(r^{*}\right)}{\partial \lambda} \neq 0
$$

at $\lambda=\lambda^{* *}$. (This is sufficient for two-period cycles.)We obtain

$$
\frac{\partial\left(f_{\lambda}^{2}\right)^{\prime}\left(r^{*}\right)}{\partial \lambda}=\frac{3(1-k)(1+k)\left(87 k^{2}-526 k+87\right)}{400 k^{2}}
$$

The numerator is zero if and only if

$$
k=1, \text { or } k=-1, \text { or } k=\frac{526 \pm \sqrt{526^{2}-4(87)^{2}}}{174}=(0.17,5.88)
$$

Thus, for all $k \in(1 / 9,9)$ except the positive roots in $(14)$, the condition (13) holds, and the result follows.

Remark 11: The condition (13) is sufficient, but not necessary, for cycles to exist. By numerical calculation, we exhibit two examples of 
cycles, where $k=1$ (i.e., the condition (13) is not met.) In both cases, $\theta$ is set at $9 / 10$, and $\lambda^{* *}$ is calculted to be 2.5. With $\lambda=2.51>\lambda^{* *}$, the proportion of apple lovers fluctuates over time in a fairly narrow band. When we pick $\lambda=2.55$, we observe that the amplitude of fluctuations becomes quite large.

\section{References}

Akerlof, G. E., and R.E. Kranton, 2000, Economics and Identity, Quarterly Journal of Economics 115, 715-753.

Arthur, W.B., 1989, Competing Technologies, Increasing Returns and Lock-in by Historical Events, Economic Journal 99, 116-31

Becker, G.,1976, Altruism, Egoism and Genetic Fitness: Economics and Sociobiology, Journal of Economic Literature 14, 817-26.

Becker, G.,1993, Nobel Lecture: The Economic Way of Looking at Behavior, Journal of Political Economy 101, 385-409.

Becker, G., and Murphy, K., 1988, A theory of Rational Addiction, Journal of Political Economy 96, 675-700.

Bergstrom, T., 1995, On The Evolution of Altruistic Ethical Rules for Sibblings, American Economic Review 85, 58-81.

Bell, A.M., 1994, Dynamically Interdependent Preferences in a General Equilibrium Environment, Typescript, Univ of WisconsinMadison.

Bhikchandani, S., Hirschleifer, D., and Welch, I., 1992, A Theory of Fads, Fashion, Custom, and Cultural Change as Informational Cascades, Journal of Political Economy 100, 992-1026.

Bisin, Alberto, and Thierry Verdier, 2000, A Model of Cultural Transmission, Voting, and Political Ideology, European Journal of Political Economy 16, 5-29. 
Bisin, Alberto, and Thierry Verdier, 2001, The Economics of Cultural Transmission and the Dynamics of Preferences, Journal of Economic Theory 97, 298-319.

Braudel, F.,1981, Civilization and Capitalism, 15th-18th Century, vol.1 : The Structure of Everyday Life, Harper and Row, New York.

Cavalli-Sforza, L.L. and M. Feldman, 1973, Cultural versus Biological Inheritance: Phenotypic Transmission from Parents to Children, American Journal of Human Genetics 25, 618-37.

Clemhout, Simone, and Henry Wan, Jr.,1970, Learning by Doing and Infant Industry Protection, Review of Economic Studies

Dawkins, Richard, 1986, The Blind Watchmaker, Longman Science and Technology, Harlow, UK.

Devaney, R., 1989, An Introduction to Chaotic Dynamical Systems, 2nd edition, Addison-Wesley, New York.

Francois, P. and T. van Ypersele, 2002, On the Protection of Cultural Goods, Journal of International Economics 56, 424-40.

Grandmont, J.-M.,1992, Transformations of the Commodity Space, Behavioral Heterogeneity and Aggregation Problem, Journal of Economic Theory 57, 1-35.

Gould, Stephen Jay, 1987, An Urchin in the Storm: Essays about Books and Ideas, Norton, New York

Hansson, I., and Stewardt, C., 1990, Malthusian Selection of Preferences, American Economic Review 80, 529-44.

Hirschleifer, J., 1977, Economics from a Biological Point of View, Journal of Law and Economics 20, 1-52. 
Hirschleifer, J., 1978, Competition, Cooperation, and Conflict in Economics and Biology, American Economic Review 68, 238-43.

Hofbauer, J, and Sigmund, K., 1988, The Theory of Evolution and Dynamical Systems, Cambridge University Press. N.Y.

Janeba, Eckhard, 2004, International Trade and Cultural Identity, Typescript, University of Colarado.

Jones, Stephen R., 1984, The Economics of Conformism, Blackwell, Oxford.

Karni, E. and Schmeidler, D., 1990, Fixed Preferences and Changing Tastes, American Economic Review Proceedings 80, 262-7.

Katz, M., and Shapiro, C., 1986, Technology Adoption in the Presence of Net work Externalities, Journal of Political Economy 94, 822,41.

Kemp., Murray C., 1960, The Mill-Bastable Infant-Industry Dogma, Journal of Political Economy 68: 65-7.

Leibenstein, H., 1950, Band wagon, Snob, and Veblen Effects in the Theory of Consumer's Demand, Quarterly Journal of Economics 64, 183-207.

Leonard, Daniel, 1989, Market Behavior of Rational Addicts, Journal of Economic Psychology 10: 117-144.

Mailath, G., 1992, Introduction: Symposium on Evolutionary Game Theory, Journal of Economic Theory 57, 259-77.

Pesendorfer, W., 1995, Design Innovation and Fashion Cycles, American Economic Review 85, 771-92.

Pollak, R.A., 1976, Interdependent Preferences, American Economic Review 66, 309-320.

Robson, Arthur, A Biological Basis for Expected and Non_Expected Utility, Journal of Economic Theory 1996, 397-424. 
Rogers, A.R., 1994, Evolution of Time Preference by Natural Selection, American Economic Review 84, 460-81.

Rogers, E.M., 1983, Diffusion of Innovations, \#rd Edition, Free Press, New York.

Schelling, T., 1978, Micromotives and Macrobehavior, Norton, New York.

Suranovic, Steve, and Robert Winthrop, 2003, Cultural Effects of Trade Liberalization, Typescript, George Washington University.

Varian, H., Microeconomic Analysis, 3rd edition, 1995, Norton, New York

von Weizsacker, Carl Christian, 1971, Notes on Endogenous Changes of Tastes, Journal of Economic Theory 3, 345-72. 


\section{CESifo Working Paper Series}

(for full list see www.cesifo.de)

1178 Stefan Lachenmaier and Ludger Woessmann, Does Innovation Cause Exports? Evidence from Exogenous Innovation Impulses and Obstacles, April 2004

1179 Thiess Buettner and Johannes Rincke, Labor Market Effects of Economic Integration The Impact of Re-Unification in German Border Regions, April 2004

1180 Marko Koethenbuerger, Leviathans, Federal Transfers, and the Cartelization Hypothesis, April 2004

1181 Michael Hoel, Tor Iversen, Tore Nilssen, and Jon Vislie, Genetic Testing and Repulsion from Chance, April 2004

1182 Paul De Grauwe and Gunther Schnabl, Exchange Rate Regimes and Macroeconomic Stability in Central and Eastern Europe, April 2004

1183 Arjan M. Lejour and Ruud A. de Mooij, Turkish Delight - Does Turkey's accession to the EU bring economic benefits?, May 2004

1184 Anzelika Zaiceva, Implications of EU Accession for International Migration: An Assessment of Potential Migration Pressure, May 2004

1185 Udo Kreickemeier, Fair Wages and Human Capital Accumulation in a Global Economy, May 2004

1186 Jean-Pierre Ponssard, Rent Dissipation in Repeated Entry Games: Some New Results, May 2004

1187 Pablo Arocena, Privatisation Policy in Spain: Stuck Between Liberalisation and the Protection of Nationals' Interests, May 2004

1188 Günter Knieps, Privatisation of Network Industries in Germany: A Disaggregated Approach, May 2004

1189 Robert J. Gary-Bobo and Alain Trannoy, Efficient Tuition Fees, Examinations, and Subsidies, May 2004

1190 Saku Aura and Gregory D. Hess, What's in a Name?, May 2004

1191 Sjur Didrik Flåm and Yuri Ermoliev, Investment Uncertainty, and Production Games, May 2004

1192 Yin-Wong Cheung and Jude Yuen, The Suitability of a Greater China Currency Union, May 2004 
1193 Inés Macho-Stadler and David Pérez-Castrillo, Optimal Enforcement Policy and Firms' Emissions and Compliance with Environmental Taxes, May 2004

1194 Paul De Grauwe and Marianna Grimaldi, Bubbles and Crashes in a Behavioural Finance Model, May 2004

1195 Michel Berne and Gérard Pogorel, Privatization Experiences in France, May 2004

1196 Andrea Galeotti and José Luis Moraga-González, A Model of Strategic Targeted Advertising, May 2004

1197 Hans Gersbach and Hans Haller, When Inefficiency Begets Efficiency, May 2004

1198 Saku Aura, Estate and Capital Gains Taxation: Efficiency and Political Economy Consideration, May 2004

1199 Sandra Waller and Jakob de Haan, Credibility and Transparency of Central Banks: New Results Based on Ifo's World Economicy Survey, May 2004

1200 Henk C. Kranendonk, Jan Bonenkamp, and Johan P. Verbruggen, A Leading Indicator for the Dutch Economy - Methodological and Empirical Revision of the CPB System, May 2004

1201 Michael Ehrmann, Firm Size and Monetary Policy Transmission - Evidence from German Business Survey Data, May 2004

1202 Thomas A. Knetsch, Evaluating the German Inventory Cycle - Using Data from the Ifo Business Survey, May 2004

1203 Stefan Mittnik and Peter Zadrozny, Forecasting Quarterly German GDP at Monthly Intervals Using Monthly IFO Business Conditions Data, May 2004

1204 Elmer Sterken, The Role of the IFO Business Climate Indicator and Asset Prices in German Monetary Policy, May 2004

1205 Jan Jacobs and Jan-Egbert Sturm, Do Ifo Indicators Help Explain Revisions in German Industrial Production?, May 2004

1206 Ulrich Woitek, Real Wages and Business Cycle Asymmetries, May 2004

1207 Burkhard Heer and Alfred Maußner, Computation of Business Cycle Models: A Comparison of Numerical Methods, June 2004

1208 Costas Hadjiyiannis, Panos Hatzipanayotou, and Michael S. Michael, Pollution and Capital Tax Competition within a Regional Block, June 2004

1209 Stephan Klasen and Thorsten Nestmann, Population, Population Density, and Technological Change, June 2004

1210 Wolfgang Ochel, Welfare Time Limits in the United States - Experiences with a New Welfare-to-Work Approach, June 2004 
1211 Luis H. R. Alvarez and Erkki Koskela, Taxation and Rotation Age under Stochastic Forest Stand Value, June 2004

1212 Bernard M. S. van Praag, The Connexion Between Old and New Approaches to Financial Satisfaction, June 2004

1213 Hendrik Hakenes and Martin Peitz, Selling Reputation When Going out of Business, June 2004

1214 Heikki Oksanen, Public Pensions in the National Accounts and Public Finance Targets, June 2004

1215 Ernst Fehr, Alexander Klein, and Klaus M. Schmidt, Contracts, Fairness, and Incentives, June 2004

1216 Amihai Glazer, Vesa Kanniainen, and Panu Poutvaara, Initial Luck, Status-Seeking and Snowballs Lead to Corporate Success and Failure, June 2004

1217 Bum J. Kim and Harris Schlesinger, Adverse Selection in an Insurance Market with Government-Guaranteed Subsistence Levels, June 2004

1218 Armin Falk, Charitable Giving as a Gift Exchange - Evidence from a Field Experiment, June 2004

1219 Rainer Niemann, Asymmetric Taxation and Cross-Border Investment Decisions, June 2004

1220 Christian Holzner, Volker Meier, and Martin Werding, Time Limits on Welfare Use under Involuntary Unemployment, June 2004

1221 Michiel Evers, Ruud A. de Mooij, and Herman R. J. Vollebergh, Tax Competition under Minimum Rates: The Case of European Diesel Excises, June 2004

1222 S. Brock Blomberg and Gregory D. Hess, How Much Does Violence Tax Trade?, June 2004

1223 Josse Delfgaauw and Robert Dur, Incentives and Workers' Motivation in the Public Sector, June 2004

1224 Paul De Grauwe and Cláudia Costa Storti, The Effects of Monetary Policy: A MetaAnalysis, June 2004

1225 Volker Grossmann, How to Promote R\&D-based Growth? Public Education Expenditure on Scientists and Engineers versus R\&D Subsidies, June 2004

1226 Bart Cockx and Jean Ries, The Exhaustion of Unemployment Benefits in Belgium. Does it Enhance the Probability of Employment?, June 2004

1227 Bertil Holmlund, Sickness Absence and Search Unemployment, June 2004 
1228 Klaas J. Beniers and Robert Dur, Politicians' Motivation, Political Culture, and Electoral Competition, June 2004

1229 M. Hashem Pesaran, General Diagnostic Tests for Cross Section Dependence in Panels, July 2004

1230 Wladimir Raymond, Pierre Mohnen, Franz Palm, and Sybrand Schim van der Loeff, An Empirically-Based Taxonomy of Dutch Manufacturing: Innovation Policy Implications, July 2004

1231 Stefan Homburg, A New Approach to Optimal Commodity Taxation, July 2004

1232 Lorenzo Cappellari and Stephen P. Jenkins, Modelling Low Pay Transition Probabilities, Accounting for Panel Attrition, Non-Response, and Initial Conditions, July 2004

1233 Cheng Hsiao and M. Hashem Pesaran, Random Coefficient Panel Data Models, July 2004

1234 Frederick van der Ploeg, The Welfare State, Redistribution and the Economy, Reciprocal Altruism, Consumer Rivalry and Second Best, July 2004

1235 Thomas Fuchs and Ludger Woessmann, What Accounts for International Differences in Student Performance? A Re-Examination Using PISA Data, July 2004

1236 Pascalis Raimondos-Møller and Alan D. Woodland, Measuring Tax Efficiency: A Tax Optimality Index, July 2004

1237 M. Hashem Pesaran, Davide Pettenuzzo, and Allan Timmermann, Forecasting Time Series Subject to Multiple Structural Breaks, July 2004

1238 Panu Poutvaara and Andreas Wagener, The Invisible Hand Plays Dice: Eventualities in Religious Markets, July 2004

1239 Eckhard Janeba, Moral Federalism, July 2004

1240 Robert S. Chirinko, Steven M. Fazzari, and Andrew P. Meyer, That Elusive Elasticity: A Long-Panel Approach to Estimating the Capital-Labor Substitution Elasticity, July 2004

1241 Hans Jarle Kind, Karen Helene Midelfart, Guttorm Schjelderup, Corporate Tax Systems, Multinational Enterprises, and Economic Integration, July 2004

1242 Vankatesh Bala and Ngo Van Long, International Trade and Cultural Diversity: A Model of Preference Selection, July 2004 